Vol. 2, No. 1, pp. 19-24, 2022

\title{
Influence of Instrumental Motivation and Integrative Motivation on English Learning Outcomes
}

\author{
Sitaresmi Imaniyati Wisnuwardhani ${ }^{{ }^{*}}$ \\ ${ }^{1}$ State Junior High School 1, Banguntapan, Bantul, Yogyakarta, Indonesia \\ *Corresponding author: sitaresmiwisnuwardhani52@guru.smp.belajar.id
}

\begin{abstract}
This research addresses students' motivation in influncing learning outcomes. The purpose of this study is to describe the students' condition of motivation in learning English whether it tends to be integrative or instrumental and the extent to which their motivation in learning English may influence students' learning outcome. This research was conducted based on principles of qualitative research. The researcher conducted an online interview to collect the data. The mid-term test grade are used as the learning outcome. Data gained in the interview and Mid-term test grade were compared and then analyzed it descriptively. Population of this study are students at grade nine. It is about 29 students in a class. The result performs that students in learning English were motivated by both instrumental and integrative motivation. That is motivation to have wider social contact with target language speakers and also motivation to utilize English as a tool to gain certain goals like good grade or future goals. Based on the findings, it is suggested that the teacher should able to motivate the students' in learning through developing his/her teaching materials concerned with integrative and instrumental motivation to motivate students' in learning English.
\end{abstract}

Keywords: instrumental motivation, integrative motivation, learning outcomes.

\section{Introduction}

Students are the center in learning process. In this process students are influenced by several factors that come from inside and outside the students. External factors consist of facilities, teachers, teaching aids, classroom situations, materials, approaches, methods, techniques, and others. These factors play an important role in the learning process. Internal factors including the physical and psychological conditions of students are very important factors influencing learning success, because students are the center of the teaching and learning process (Mirhadizadeh, 2016).

One of the psychological aspects of students in learning is motivation. Motivation is considered to play a major role in the learning process, because the success of all human activities is heavily influenced by the underlying motives. Motivation influences a person's behavior and directs them and supports sustainability (Moos \& Marroquin, 2010). Motivation functions as energy from within students that moves them to take certain actions to achieve something they want. It can be said that motivation in learning is related to the desire to learn, this is the main basis for successful learning.

In a foreign language learning motivation is also needed. This is in accordance with the statement of Terrel and Brown that motivation is the key to success in foreign language learning (Terrell \& Brown, 1981). Some educators, for example Gardner and Lambert in Marosan \& Markovic, (2019) put forward a concept which they call integrative motivation and the concept of instrumental motivation. Instrumental motivation refers to the motivation to acquire language as a means to advance a particular career. Integrative motivation is used when students want to integrate themselves into the culture of another language group and become part of that society. Gardner adds that integratively oriented learners are likely to have a stronger desire to learn a language, have a more positive attitude towards learning situations, and are more likely to expend more. In language learning integrative motivation may indeed be an important requirement for successful language learning. Based on this theory, the researcher formulates the problem, namely which type of motivation to learn English affects the outcomes of learning English? Is it instrumental motivation or integrative motivation?

There are two types of motivation in learning English, namely instrumental motivation and integrative motivation. Therefore, this study is limited to investigating which types of motivation to learn English affect English learning 
outcomes. Limitation of the problem is needed, therefore the research becomes more focused to achieve research objectives.

The purpose of this study is to reveal the condition of students' motivation in learning English, both instrumental motivation and integrative motivation and their influence on learning outcomes. The results of this study will make teachers aware of the importance of motivation in learning English. Teachers are expected to make improvements that can motivate students in learning English. Teachers can enrich English subject matter which can increase motivation in learning English.

\section{Materials and Methods}

\subsection{Materials}

This research was conducted at SMP 1 Banguntapan Bantul in the odd semester of the 2021-2022 academic year. The population in this study is a ninth grade, with a total of 29 students. The class was chosen because the score was evenly distributed between high scores, middle grades and scores below the minimum completeness score (75). Midsemester test scores are taken as learning outcomes. Some basic competencies have been assessed through a midsemester assessment. Therefore, the value of the mid-semester assessment can represent the learning outcomes of students. Participants were grouped based on the mid-semester score range, namely, high scores (100-85), medium scores (84-75) and low scores (74-55) or below the minimum completeness score. Table 1 is the distribution of the number of students' scores per grade category.

Table 1: Number of Students per Grade Category

\begin{tabular}{c|c}
\hline Range of Grades & Number of Students \\
\hline $100-85$ & 9 \\
$84-75$ & 12 \\
$74-55$ & 8 \\
Sum & 29 students' \\
\hline
\end{tabular}

\subsection{Methods}

This study describes the learning motivation of students. The qualitative design was implemented to explore the phenomena using words, stories, and pictures (Creswell, 2012). Therefore this research was conducted based on the principles of qualitative research design. Qualitative research has a descriptive nature and tends to use analysis to draw generally accepted conclusions from specific events, so that processes and meanings based on the subject's point of view are prioritized. This qualitative research design can be used as a method in research. It facilitated the understanding of the meaning from the obtained phenomenon, the explanation of the existing issues, and giving solution (Gillham, 2000).

Data collecting technique is by conducting online interviews to reveal the type of motivation. The research is evaluated by the Situational Motivation Scale (SIMS), developed by Guay, Vallerand, and Blachard (2000), and Degang's (2020) Likert scale. The questions given are about instrumental motivation and integrated motivation. Given 3 choices of answers to these questions, namely Strongly Agree, Agree and Disagree to find out the attitudes and opinions of students about the two types of motivation. The results of the interviews are then analyzed descriptively qualitatively. Maintaining the Integrity of the Specifications.

\section{Results and Discussion}

The researcher conducted interviews by giving several questions that are made according to the type of motivation. There are 10 questions, 5 questions about instrumental motivation and 5 questions about integrative motivation. Table 2 is a list of questions about instrumental motivation and integrative motivation based on the theory of Gardner and Lambert. 
Table 2: Questions on Instrumental and Integrative Motivation

\begin{tabular}{|c|c|}
\hline Instrumental Motivation & Integrative Motivation \\
\hline 1. I study English because my future goal is & 1. I learn English so I can communicate with many \\
\hline $\begin{array}{l}\text { 2. I study English because English is a compulsory } \\
\text { subject at school. }\end{array}$ & $\begin{array}{l}\text { 2. I study English because I also want to learn the } \\
\text { culture of countries that use English. }\end{array}$ \\
\hline $\begin{array}{l}\text { 3. I study English because in higher education I } \\
\text { need English. }\end{array}$ & $\begin{array}{l}\text { 3. I learn English because I want to see English films } \\
\text { without seeing subtitles. }\end{array}$ \\
\hline 4. I study English to get good grades. & 4. I like to learn English. \\
\hline 5. I study English so I can work abroad. & $\begin{array}{l}\text { 5. I study English because I really like English, not } \\
\text { just because I have to. }\end{array}$ \\
\hline
\end{tabular}

\subsection{Research Result}

Figure 1 displays the results of interviews with students, and the results obtained are as in the table below.

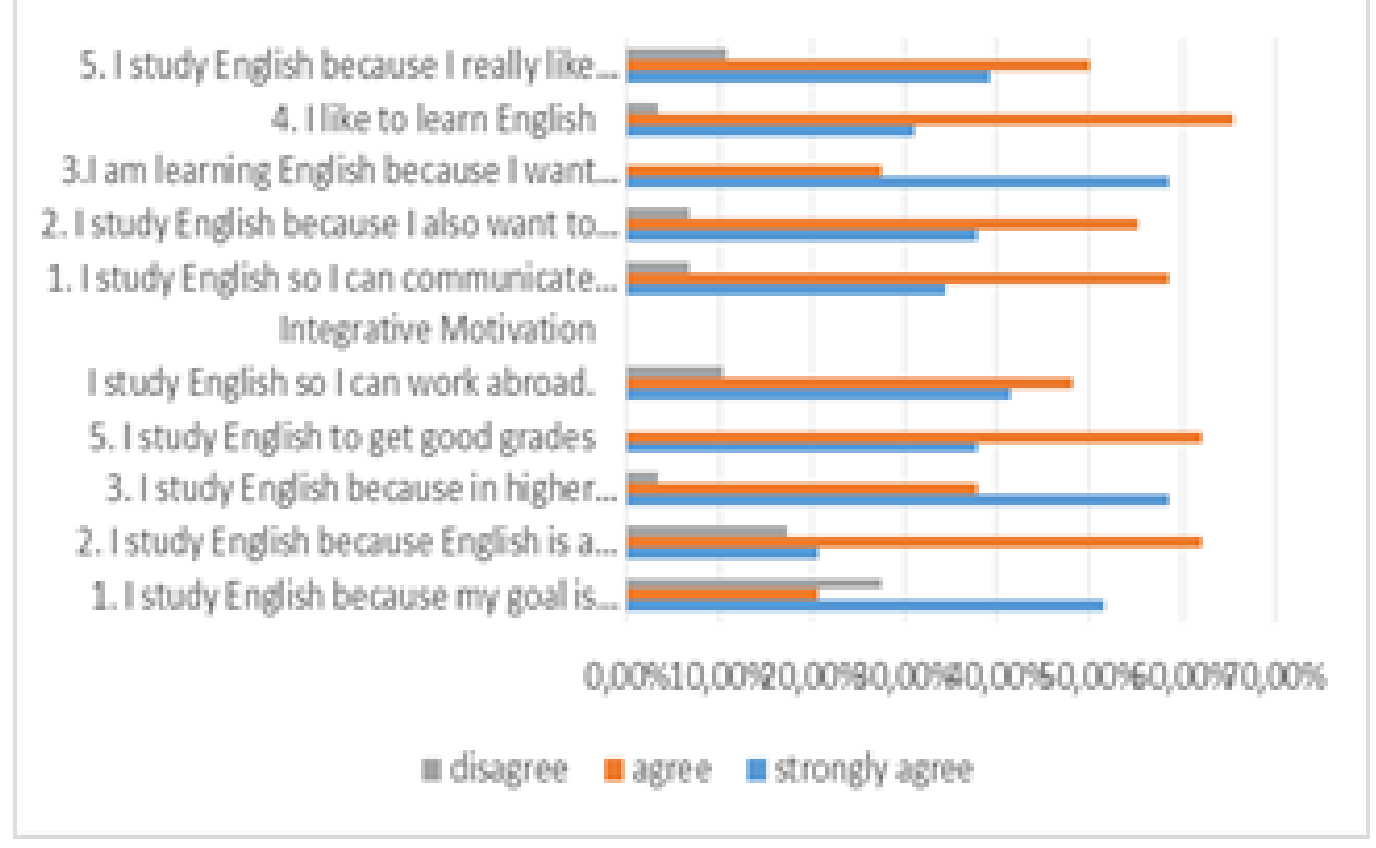

Figure 1: Interview Results about Instrumental and Integrative Motivation

\subsubsection{Instrumental Motivation}

1. Question No.1 about ideals related to English shows the percentage of $51.70 \%$ for strongly agree, $20.7 \%$ agree, and $27.6 \%$ disagree. This percentage indicates that students are instrumentally motivated. Where students learn English as a means to achieve their goals.

2. Question No.2 about liking English because it is a compulsory subject in school shows the percentage of $20.7 \%$ to strongly agree, $62.1 \%$ to agree and $17.3 \%$ to disagree. The high percentage of agree can also show that students are instrumentally motivated even though the level is not too strong.

3. Question No.3 about the English language needed in higher education shows the percentage strongly agree $58.6 \%$, agree $37.9 \%$, disagree $3.4 \%$. The figure of $58.6 \%$ clearly shows that students are instrumentally motivated, that is learning English as a means to continue their education.

4. Question No.4 about learning English in order to work abroad shows a percentage of $41.4 \%$ to strongly agree, agree $48.3 \%$, disagree $10.3 \%$. The same high percentage of strongly agree and agree indicates that students are instrumentally motivated, that is learning English to get a certain job. 
5. Question No.5 About learning English with the aim of getting good grades shows $37.9 \%$ strongly agree, $62.1 \%$ agree and no one answered disagree. In percentage terms, it can be said that students are instrumentally motivated, that is learning English to get the maximum score.

\subsubsection{Integrative Motivation}

1. Question No.1 about learning English to be able to master the target language in order to communicate with many people in the world shows the percentage strongly agree $34.5 \%$, agree $58.6 \%$, disagree $6.9 \%$. This percentage shows that students are integratively motivated. Where students learn English as a communication tool.

2. Question No. 2 about learning English while learning the culture of the country of the target language shows $37.9 \%$ strongly agree, $55.2 \%$ agree, $6.9 \%$ disagree. This percentage shows that students are integratively motivated, that is wanting to be part of the target language community.

3. Question No. 3 about studying because they want to see English films without seeing subtitles shows $58.6 \%$ to strongly agree, 27.6 agree and 13.8 agree. This shows that students are highly motivated integratively. Where the desire to understand the target language and use it in everyday life.

4. Question No. 4 on whether students like English lessons shows a figure of 31\% strongly agree, $65.5 \%$ agree, and $3.4 \%$ disagree. This figure shows integrative motivation, which is indeed liking the target language without having certain targets.

5. Question No.5 about learning English is not only because of obligation but because of liking English shows the numbers strongly agree $39.3 \%$, agree $50 \%$ and disagree 10.7 . This shows that students are motivated integratively with a level that is not too strong.

\subsection{Analysis of the Interview Result and Student Learning Outcomes}

The researcher then, analyze the interview result with the mid-term test score. The result are seen in the Figure 2.

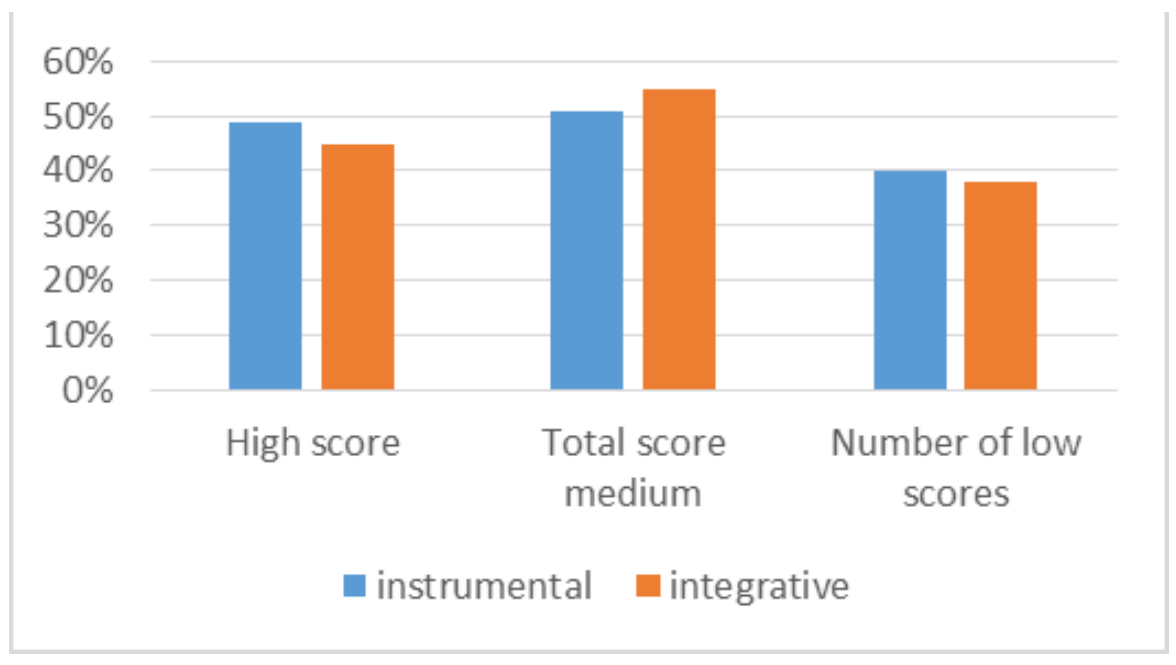

Figure 2: Analysis of the Results of Interviews and Student Learning Outcomes

Based on the Figure 2, the category of students with high scores indicates that the percentage of instrumental motivation is higher than that of integrative motivation. Instrumental motivation is at a score of $49 \%$, while integrative motivation is at a difference of $4 \%$, namely $45 \%$. This difference can be used to show that students who get good learning outcomes are more motivated instrumentally. The desire to obtain maximum learning outcomes and the desire to further study or get a job abroad lead to increased enthusiasm for learning English. This is in line with the statement of researchers in the same field about learning motivation in English for first-year medical students conducted by Marosan and Markovic (2019), namely that high instrumental motivation will make the spirit of learning English like learning terms in the medical world in English to be higher.

In the category of students with intermediate grades, it shows that the percentage of integrative motivation is at a higher number, that is $55 \%$. As for instrumental motivation, the percentage is slightly below that at $51 \%$. This shows that $4 \%$ more integrative motivation is owned by students. Integrative motivation where students want to learn 
English to understand the target language community/social culture, has shown a significant influence on learning outcomes. The value is already in the range of values above the minimum completeness score. There is a question why students who are said to be integratively motivated have not been able to get maximum scores. This can be used as a consideration for teachers to review materials and methods that are more appropriate for students who are integratively motivated to improve their learning outcomes.

In the category of students with learning outcomes under the passing grade or minimum completion score, the percentage is almost the same between instrumental motivation and integrative motivation. Instrumental motivation is $40 \%$ and integrative motivation is $38 \%$. Instrumental motivation is only $2 \%$ higher. This shows that these two types of motivation do not significantly affect the learning outcomes of students whose scores are below the passing grade. It can be said that students whose learning outcomes are below the passing grade have not shown what kind of motivation affects their learning outcomes. Students do not know what their main purpose for learning English is. Is it to get good grades or with the aim of getting to know the language itself in depth. So that the achievement of student learning outcomes in this category is not optimal.

\section{Conclusion and Recommendation}

\subsection{Conclusion}

Both types of motivation to learn English, namely instrumental and integrative motivation have an effect on student learning outcomes. It can be seen from the graph that the percentage of instrumental and integrative motivation shows only a slight difference. Although students whose learning outcomes show high scores are more instrumentally motivated. Students with learning outcomes in the category of medium grades tend to be integratively motivated. For students with scores below the passing grade, they are motivated by both types of motivation, both integrative and instrumental.

The difference in the percentage of very little or less than $5 \%$ in the interview results between instrumental motivation and integrative motivation shows that instrumental motivation and integrative motivation show the same high level. The conclusion is that students in learning English are motivated instrumentally and integratively. Students in learning English have the desire to master the target language as a means of communication and also to master the target language as a means of pursuing good learning outcomes and goals.

\subsection{Recommendation}

Knowing the condition of the motivation to learn English, the english teacher can arrange interesting learning materials for students to learn English. These materials can motivate students' learning both instrumentally and integratively. For students who are integratively motivated, the teacher can enrich vocabulary in English through texts about the culture of the target language. Through a short learning video in the form of a native speaker's role play to show how to communicate properly and correctly with the target language. Teacher can also find links for pen pals to improve writing skills directly with native speakers. So that those who are integratively motivated can learn English by feeling directly involved in the target language community.

For students who are instrumentally motivated, interesting things like the example above will further increase their learning motivation. Learning resources other than varied textbooks will make students feel that learning English is not only an obligation but also a joy. This research can give contributions for other research in motivation. The researchers can provide deeper questions to reveal instrumental and integrative motivation.

\section{References}

Creswell, J. W. (Eds.). (2012). Educational research: planning, conducted and evaluating quantitative and qualitative research. Boston, MA: Pearson.

Degang, M. (2020). Motivation toward English language learning of the second year undergraduate Thai students majoring in Business English at English medium university. Bangkok: Srinakharinwirot University.

Gillham, B. (2000). Case study research. London: Continuum.

Guay, F., Vallerand, R. J., \& Blanchard, C. (2000). On the assessment of situational intrinsic and extrinsic motivation: The Situational Motivation Scale (SIMS). Motivation and Emotion, 24(3), 175-213. http://doi.org/10.1023/A:1005614228250.

Marosan, Z., \& Markovic, V. (2019). Instrumental and integrative motivation in teaching English for medical purposes. Medicinski Pregled, 72(3-4). https://doi.org/10.2298/mpns1904098m 
Mirhadizadeh, N. (2016). Internal and External Factors in Language Learning. International Journal of Modern Language Teaching and Learning. available nnline at www.ijmltl.Com, 1.

Moos, D. C., \& Marroquin, E. (2010). Multimedia, hypermedia, and hypertext: Motivation considered and reconsidered. In Computers in Human Behavior (Vol. 26, Issue 3). https://doi.org/10.1016/j.chb.2009.11.004

Terrell, T. D., \& Brown, H. D. (1981). Principles of Language Learning and Teaching. Language, 57(3). https://doi.org/10.2307/414380 